How to Cite

Sarada, V., \& Mallikarjuna, T. (2018). Socio-economic and psychological problems of third gender people living with

HIV/AIDS: A study in A.P. International Journal of Health \& Medical Sciences, 1(1), 10-17.

https://doi.org/10.31295/ijhms.v1n1.34

\title{
Socio-Economic and Psychological Problems of Third Gender People Living with HIV/AIDS: A Study in A.P.
}

\author{
V. Sarada \\ Doctoral Fellow, Dept of Women's Studies, SPMVV Tirupati \\ Corresponding author email: tmallikarjuna.malli1@gmail.com \\ T. Mallikarjuna \\ Doctoral Fellow, Dept of Sociology, S.V. University Tirupati
}

\begin{abstract}
Transgender means that one doesn't view their birth gender as their "true" or "real" gender. Instead, a transgender person finds his or her true "self" somewhere along the spectrum of a wider concept of gender. Transgender people living with HIV/AIDS generally face gender identity crisis. Gender identity refers to a person's internal deeply felt sense of being either male or female. Their gender expressions are different. Gender identity is internal and personally defined. Gender expression is external and socially perceived either masculine or feminine. Due to their gender identity crisis, they bear the brunt of social, economic and cultural marginalization and discrimination. The Supreme Court given favorable judgment on 15th April, 2014 and stated that these Transgender people should be recognized as" Third gender people or third sex". It provided legal protection to them by giving education and employment opportunities to them and also any reservation in jobs etc., It also recognized their citizenship as par with other citizens of the country. The Supreme Court declared that they have reservation in education as well as employment opportunities. Welfare activities should be provided by the Central and State Governments. Trans Genders are high risk population in spreading HIVIAIDS. However, they don't have any awareness on safe methods of following sexual behavior because of illiterate. The recent Supreme Court judgment was also not known to them due to lack of proper education. The police, Doctors, lawyers and the Government employers are the four pillars of our society. However, these people are discriminated by them and they don't have necessary protection in the society. Family members often do not support transgender. A variety of problems that include verbal and physical abuse, isolation and rejection, denial of family property are faced by transgender in family. Society often stigmatizes and discriminate transgender based on their sexuality or gender identity. Social stigma includes being looked down upon, labeling and negative/generalized attitude towards such as sex work or sex solicitors. Most of the transgender people are school dropouts. Similarly, gays and bisexuals especially after voluntary or involuntary disclosure of their sexuality face a lot of stigma and discrimination in schools. Lack of adequate education and lack of employment opportunities, they are forced into sex work and begging. The present study critically evaluates the third gender socio and psychological problems in faced by the society.
\end{abstract}

Keywords---Health, HIV/AIDS, legal protection, Psychological.

\section{Introduction}

Gender expression includes all of the external personal characteristics that are visible to others: appearance, clothing, mannerisms, and behaviors. Sexual orientation refers to whether a person is attracted to men, women or to both. A person's internal feelings and the labels they use, such as male, female, or transgender. Everyone, of course, has a sex, a gender identity, a gender expression, and a sexual orientation. Just how all those factors are related, or what causes any given individual to have the particular mix of characteristics that define his or her identity, is not yet known and may never be known. What is known, however, is that there is no necessary connection between a

ISSN 2632-9433

Received Jan 10, 2018 / Accepted Jun 20, 2018 / Published Jul 05, 2018 
person's gender identity, gender expression, and sexual orientation? Gender identity and transgender are different from sexual identity and lesbian, gay and bisexual

Definition and Concept of Transgender Trans Gender mean of or relating to people who have a sexual identity that is not clearly male or clearly female. Of, relating to, or being a person (as a transsexual or transvestite) who identifies with or expresses a gender identity that differs from the one which corresponds to the person's sex at birth. Transgendered people have existed in every culture, race, and class since the story of human life has been recorded.

Transgender people have a way of expressing themselves, describing their gender or gender identity (Knowing that he/she is a boy or girl) that doesn't all Transgender, or Trans: means someone whose gender differs from the one they were given when they were born. Transgender people may identify as male or female, or they may feel that neither label fits them. Transition: In order to express their chosen gender, transgender people may transition, or change, from the gender they were given at birth. They may change their names, pronouns or style of dress. Some transgender people also choose a medical transition, with the help of medical specialists, who will prescribe hormones and/or surgery.

\section{Meaning of Transgender}

Many gay, lesbian, and bisexual (GLB) people are taking on the transgender label because their gender presentation crosses arbitrary boundaries that they want to render less constraining, or because they recognize that loving a person of the same sex is in itself a challenge to dominant gender norms. The term transgender is generally used to describe those who transgress social gender norms. Transgender is often used as an umbrella term to signify individuals who defy rigid, binary gender constructions and who expresses or present a breaking and blurring of culturally prevalent stereotypically gender roles.

It includes pre-operative, post-operative and non- operative transsexual people who strongly identify with gender opposite to their biological sex (UNDP India Report, 2010).

\section{Medical Definition of the Transgender}

The medical definition of Transgender is as follows.

Male-to-female transsexual (MTF) people are born with male bodies but have a female gender identity. Many, but not all, transsexual people undergo medical treatment to change their physical sex through hormone therapy and sex reassignment surgeries. Female-to-male transsexual people are rarely mentioned in contemporary discussions of transsexual lives.

Other current synonyms for transgender include "gender variant," "gender different," and "gender nonconforming." Transgender In its broadest sense encompasses anyone whose identity or behavior falls outside of stereotypical gender norms and changed their sex, implying the broader social awareness and may have as a result of experiencing life from within two kinds of (perceived) bodies, though their gender identity may always have remained the same.

\section{Attitudes, cultural and Behavioral patterns of the Trans Gender}

Unlike normal human being, the Transgender/hijras have different kind of Attitudes, cultural and behavioral patterns. In Tamilnadu and in South Asia, they celebrate the ceremonies as following way.

Each year in Tamil Nadu, during April and May, Trans Genders/Hijras celebrate an eighteen-day religious festival. The aravani temple is located in the village Koovagam in the Ulundurpet taluk in Villupuram district and is devoted to the deity Koothandavar, who is identified with Aravan. During the festival, the aravan is reenact a story of the wedding of Lord Krishna and Lord Aravan, followed by Aravan's subsequent sacrifice. They then mourn Aravan's death through ritualistic dances and by breaking their bangles. An annual beauty pageant is also held, as well as various health and HIV or AIDS seminars. Hijras from all over the country travel to this festival.

A personal experience of the hijras in this festival is shown in the BBC Three documentary India's Ladyboys and also in the National Geographic Channel television series Taboo. Trans Genders/Hijras have a recorded history in the Indian subcontinent, from antiquity, as suggested by the Kama Sutra period, onwards. This history features a number of well-known roles within subcontinental cultures, part gender-liminal, part spiritual, and part survival.

In South Asia, many Trans Genders/hijras live in well-defined and organized all such type of communities, led by a guru. These communities have sustained themselves over generations by "adopting" young boys who are rejected by, or flee their family of origin. Many works as sex workers for survival. 
The word "hijra" is an Urdu-Hindustani word derived from the Semitic Arabic root hjr in its sense of "leaving one's tribe," and has been borrowed into Hindi. The Indian usage has traditionally been translated into English as "eunuch" or "hermaphrodite," where "the irregularity of the male genitalia is central to the definition." However, in general, Trans Genders/hijras are born with typically male physiology, only a few having been born with male intersex variations. Some Hijras undergo an initiation rite into the Trans Genders/hijra community called nirwaan, which refers to the removal of penis, testicles, and scrotum.

Since the late 20th century, some hijra activists and Western non-government organizations (NGOs) have lobbied for official recognition of the hijra as a kind of "third sex" or "third gender," as neither man nor woman. Hijras have successfully gained this recognition in Bangladesh and are eligible for priority in education In India, the Supreme Court in April 2014 recognized hijra and transgender people as a 'third gender' in law.

The Transgender people or Hijras are called by the community in different forms at different places in different languages as follows.

The Urdu and Hindi word hijra may alternately be romanized as hijira, hijda, hijada, hijara, hijrah and is pronounced. This term is generally considered derogatory in Urdu and the word Khwaja Saraa is used instead. Another such term is khasu) or khusaraa (. In Bengali hijra is called, hijra, hijla, hijre, hizra, or hizre. A number of terms across the culturally and linguistically diverse Indian subcontinent represent similar sex or gender categories. While these are rough synonyms, they may be better understood as separate identities due to regional cultural differences. In Telugu, a Trans Genders/hijra is referred to as napunsakudu Kojja or maada In Tamil Nadu the equivalent term is Thiru nangai (mister woman), Ali, aravanni, aravani, or aruvani. In Punjabi, both in Pakistan and India, the term khusra is used. Other terms include jankha. In Gujarati, they are called pavaiyaa.

In North India, the goddess Bahuchara Mata is worshipped by Pavaiyaa. In South India, the goddess Renuka is believed to have the power to change one's sex. Male devotees in female clothing are known as Jogappa. They perform similar roles to hijra, such as dancing and singing at birth ceremonies and weddings.

The AIDS epidemic has had a unique impact on women, which has been exacerbated by their biological vulnerability to HIV infections. Generally, women are at a greater risk of heterosexual HIV. Biologically women are twice more likely to become infected with HIV through unprotected heterosexual intercourse than men. In many countries, women are less likely to be able to negotiate condom use and are more likely to be subjected to nonconsensual sex. Additionally, millions of women have been indirectly affected by the HIV/AIDS epidemic. Women's childbearing role means that they have to contend with issues such as mother-to-child transmission of HIV. The responsibility of caring for AIDS patients and orphans is also an issue that has a greater effect on women. There is a number of things that can be done in order to reduce the burden of the epidemic among women. These include promoting and protecting women's human rights, increasing education, and awareness among women encouraging the development of new preventative technologies such as post-exposure prophylaxis and micro biocides. While the effects of HIV/AIDS are equally detrimental for all persons affected or infected, certain sections of the population, across the world, however, are more vulnerable in terms of both, contrasting the infection the subsequent consequences. Both structural (psycho-socio) and cultural (traditional norms etc.) factors are responsible for rendering certain sections like women, commercial sex workers, youth, migrants, orphans, children and dependants of family members who are positive, more vulnerable than others. Women whether, married/single, divorced/widowed, sex workers or seasonal migrants or adolescent girls, are most susceptible to the negative impacts-direct or indirect, i.e. infected or affected, of HIV and AIDS owing to the dynamics between the structural and cultural factors which places them in a weaker and vulnerable position than most others. Further, women are biologically more prone to HIV infections than men in terms of any single act of unprotected sex with an infected

partner with the male- to female transmission of the virus being 2 to 4 times higher than the female to male transmission among such serodiscordant couples. The biological structure of women thus also renders more vulnerable than others to HIV and AIDS.

The objective of the Study

The study mainly focuses on the present socio-economic and psychological status of the third gender in society.

\section{Research Method}

The study is organized with the help of secondary data collected from articles, publications and study materials. 


\section{Results and Analysis}

\section{Transgender in India}

Indian Census has never recognized the third gender i.e. Transgender while collecting census data for years. But in 2011, data of Transgender's were collected with details related to their employment, Literacy, and Caste. In India, the total population of transgender is around 4.88 Lakh as per 2011 census.

Table 1

Lakh as per 2011 census

\begin{tabular}{lllllll}
\hline S.No & state & Transgender & Child(0-6) & SC & ST & Literacy \\
\hline$\#$ & India & 487,803 & 54,854 & 78,811 & 33,293 & $56.07 \%$ \\
1 & Uttar Pradesh & 137,465 & 18,734 & 26,404 & 639 & $55.80 \%$ \\
2 & Andhra Pradesh & 43,769 & 4,082 & 6,226 & 3,225 & $53.33 \%$ \\
3 & Maharashtra & 40,891 & 4,101 & 4,691 & 3,529 & $67.57 \%$ \\
4 & Bihar & 40,827 & 5,971 & 6,295 & 506 & $44.35 \%$ \\
5 & West Bengal & 30,349 & 2,376 & 6,474 & 1,474 & $58.83 \%$ \\
6 & Madhya Pradesh & 29,597 & 3,409 & 4,361 & 5,260 & $53.01 \%$ \\
7 & Tamil Nadu & 22,364 & 1,289 & 4,203 & 180 & $57.78 \%$ \\
8 & Orissa & 20,332 & 2,125 & 3,236 & 4,553 & $54.35 \%$ \\
9 & Karnataka & 20,266 & 1,771 & 3,275 & 1,324 & $58.82 \%$ \\
10 & Rajasthan & 16,517 & 2,012 & 2,961 & 1,805 & $48.34 \%$ \\
\hline
\end{tabular}

The Third Gender in our country- 4.9 lakh. While transgender activists estimate the numbers to be six to seven times higher, they are thrilled that such a large number of people identified themselves as belonging to the third gender, despite the fact that the census counting happened well before the Supreme Court order gave legal recognition to the third gender in April this year. Of the total number of transgenders identified by the census, almost 55,000 are in the 0-6 population. This has come as a big surprise to the community as they did not expect so many parents to identify their children as belonging to the third gender.

"After the disappointment of the election commission's efforts, this is fantastic news for the transgender community. We were extremely disappointed because during the voter registration process only 28,341 people registered as belonging to the third gender," said Kalki Subramaniam, transgender rights activist and founder of the Sahodari Foundation. She added that she was even more amazed that parents would come out and accept and identify their children as being transgender. Anjali Gopalan of Naz Foundation said that even the current figure of 4.9 lakh was on the lower side as it was unlikely that the number of people declaring themselves as transgender would ever give an accurate figure.

Over $66 \%$ of the population identified as the third gender lived in rural areas, very close to the $69 \%$ of the overall population that lives in villages. The census data also revealed the low literacy level in the community, just $46 \%$, compared to 74\% literacy in the general population. "I am not surprised that the literacy rate is so low because it is not uncommon at all for people of transgender to drop out of school because of the harassment and discrimination they face."

The highest proportion of the third gender population, about $28 \%$, was identified in Uttar Pradesh followed by 9\% in Andhra Pradesh, 8\% each in Maharashtra and Bihar, over 6\% in both Madhya Pradesh and West Bengal and well over $4 \%$ in Tamil Nadu, Karnataka, and Odisha. Rajasthan accounted for over 3\% of the total transgender population and Punjab for $2 \%$. The proportion of those working in the transgender community is also low (38\%) compared to $46 \%$ in the general population. Only $65 \%$ of the total working population are main workers those who find work for more than six months in the year - compared to $75 \%$ in the general population.

\section{Society and transgender}

Most families do not accept if their male child starts behaving in ways that are considered feminine or inappropriate to the expected gender role. Consequently, family members may threaten, scold or even assault their son/sibling from behaving or dressing up like a girl or woman. Some parents may outright disown and evict their own child for crossing the prescribed gender norms of the society and for not fulfilling the roles expected of a male child. Parents may provide several reasons for doing so: bringing disgrace and shame to the family; diminished chances of their 
child getting married to a woman in the future and thus end of their generation (if they have only one male child); and perceived inability on the part of their child to take care of the family. Thus, later transgender women may find it difficult even to claim their share of the property or inherit what would be lawfully theirs. Sometimes, the child or teenager may decide to run away from the family not able to tolerate the discrimination or not wanting to bring shame to one's family. Some of them may eventually find their way to Hijra communities. This means many Hijras are not educated or uneducated and consequently find it difficult to get jobs. Moreover, it is hard to find people who employ Hijras/TG people. Some members of the society ridicule gender-variant people for being 'different' and they may even be hostile. Even from police, they face physical and verbal abuse, forced sex, extortion of money and materials; and arrests on false allegations. The absence of protection from police means ruffians find Hijras/TG people as easy targets for extorting money and as sexual objects. Some of the studies documented that in the past one year, the percentage of those MSM and Hijras who reported: forced sex is $46 \%$; physical abuse is $44 \%$; verbal abuse is $56 \%$; blackmail for money is $31 \%$, and a threat to life is $24 \%$.

Most hijras live at the margins of society with very low status; the very word "hijra" is sometimes used in a derogatory manner. The Indian lawyer and author Rajesh Talwar have written a book highlighting the human rights abuses suffered by the community titled 'The Third Sex and Human Rights.' Few employment opportunities are available to hijras. Many get their income from extortion (forced payment by disrupting work/life using demonstrations and interference), performing at ceremonies (toli), begging (dheengna), or sex work ('raarha')—an occupation of eunuchs also recorded in premodern times. Violence against hijras, especially hijra sex workers, is often brutal and occurs in public spaces, police stations, prisons, and their homes. As with transgender people in most of the world, they face extreme discrimination in health, housing, education, employment, immigration, law, and any bureaucracy that is unable to place them into male or female gender categories.

\section{Social problems of the third gender}

The identification crisis and the reactions by the society form the baseline of the different social problems faced by $\mathrm{TG}^{\text {ee }} \mathrm{s}$. When they realize that there is a mismatch between their biological identity (sex) and gender they are subject to eve teasing and discrimination. Even close family members do not understand and are not willing to accept them. As a result, they migrate to cities and faraway places. There are differences in the way people perceive the TGers. It was understood that rural people accept and treat them as individuals in a better way than the urban ones. Most of the $\mathrm{TG}^{\text {ee }} \mathrm{s}$ crave for identification. They wanted to be treated as normal individuals. They suffer without a companion for life. Due to this, they cannot form a social unit which leaves them isolated. However, there are very few TGes who are married and leading a normal life. The problem of exploitation and harassment from different social agents is an inevitable part of their lives. They narrate experiences of having beaten up by their gurus and police of the Ephemeris locality. Out of their everyday earnings, they are bound to give a proportion of it to their gurus. Even if employed somewhere, there are instances of the so-called educated ones in corporate firms having teased TG's due to which they have left the jobs.

Community-level barriers: Failure to provide free SRS in government hospitals and inadequate personal resources to pay for gender transition-related services in private hospitals seems to be the key reasons why many hijras and MtF transgender people choose Dai Nirvan or go to quacks for emasculation. Besides the cost factor, some hijras seem to prefer Dai Nirvan for other reasons as well: no bureaucratic 'approval' for hospital-based surgery; personalized care by fellow community members; lack of discrimination; and no refusal when someone is HIVpositive. Many hijras believe that those who undergo Dai Nirvan will be more feminine than those who undergo surgery by a qualified medical practitioner. Such beliefs in the community and the social pressure they create often discourage hijras from seeking services from qualified surgeons.

Individual-level barriers: An unknown but significant proportion of hijra-identified persons appear to opt for traditional Dai Nirvan partly because free SRS is not available in government hospitals, and these services are too expensive in private hospitals. MtF transgender people in rural areas and small towns are typically unaware of modern SRS procedures available in city hospitals. Many hijras are also unable to afford the costs of physicianprescribed hormonal therapy and often rely on peer knowledge and experience in using specific brands and dosages of female hormonal tablets or injections. As a result, they face a high risk of adverse effects due to overzealous or incorrect dosages and interactions with other medications, such as antiretroviral treatment for HIV infection. 
Economic problems of the third gender

Most of the individuals who identified themselves as transgenders faced the problem of an identity crisis at puberty. This created hurdles for continuing their education. Unable to handle the discrimination in the places of education, they are branded as „dropoutse, „lacking qualification. “ Due to lack of academic qualification, they do not have market value to acquire good jobs and because of their gender identity, they are not employed anywhere. As a result, they are involved in begging and sex work to earn income for their living. They also choose this occupation as they are in need of finance to fund their operations for a change of sex organs. Few of the TG $\mathrm{G}^{\text {ee }} \mathrm{s}$ set up their own business, like fruit sellers or vegetable vendors. Firstly, they do not have access to credit to invest and no reliable collaterals to seek loans. Even if they manage to access credit and invest they cannot sustain the business because of very high rent. The cost of running a small shop is up to fifty thousand or more which is not affordable for them. From the data collected it is accounted that there are about five thousand transgenders in Andhra Pradesh. They do not have any proof for their identification restricting their access to all provisions and amenities. Recently, there has been an attempt to provide PAN card, ration card, voter id to recognize the third gender, nevertheless the entire community is not covered. This problem again enhances the difficulty of obtaining credit.

Employment: The constitutional provisions clearly state that discrimination should not be practiced on any grounds to people in terms of job opportunities. But a stable livelihood option for transgenders is too scarce. There are very few who have been employed in the mainstream in Andhra Pradesh, one is a typewriter in High Court, another employed as a radio jockey. Most of the TG's are aware of the health risks of doing sex work. They resort to sex work or begging only for survival. Since the skill levels are very low, they can be employed in the production related to small-scale industries like candle making, camphor making, agarbattis, attendees, sweepers. Many of them are also aware of creative skills needed for Mehendi, painting and parlor.

Housing: Tran's people may be particularly at risk of housing crisis and homelessness arising from transphobic reactions and harassment by family, neighbors, and members of their local community. Morton 2008 reported that 25.4 percent of respondents had to move out of their home due to transphobic reactions. There were no housing services specifically addressing the needs of trans people and access to housing services was not monitored in relation to trans status or gender identity. Tran's people fear disclosing their identity to housing officers for fear that they will not be treated with dignity and respect. The result can be that they do not receive the housing services that they need or receive a service inappropriate to their needs.

\section{Psychological and Biological problems of the third gender}

The whole process of coming out from their zones and revealing their identity needs a lot of courage. The process of undergoing sexual surgery too brings in a lot of stress physiologically and psychologically. Most of the time, it becomes difficult due to lack of support from family or friends. They refuse to do jobs in the formal sector even if they are qualified due to discrimination and eve teasing. They manage odd jobs for a living which they are not happy. Feeling of loneliness due to lack of companion and just the lack of feeling of normality in leading a life is the reason they just survive and not live their life.

Transgender identity is not a mental illness that can be cured with treatment. Rather, transgender people experience a persistent and authentic difference between our assigned sex and our understanding of our own gender. For some people, this leads to emotional distress. This pain often can be relieved by freely expressing our genders; wearing clothing we are comfortable in, and, for some, making a physical transition from one gender to another. For people who identify as transsexual, counseling alone, without medical treatment, is often not effective. Our society is, however, very harsh on gender-variant people. Some transgender people have lost their families, their jobs, their homes and their support. Transgender children may be subject to abuse at home, at school or in their communities. A lifetime of this can be very challenging and can sometimes cause anxiety disorders, depression, and other psychological illnesses.

Structural and legal barriers: Lack of a health policy on gender transition-related services at national-level and guidelines on standards of care for transgender people who require such services is a critical issue. Interviews with psychiatrists and surgeons who perform SRS indicated that many healthcare providers may not be aware of the authoritative guidance document from the World Professional Association for Transgender Health (WPATH), Standards of Care for the Health of Transsexual, Transgender, and Gender-Nonconforming People, which is now in its seventh edition. Ambiguity about the legal status of SRS and other services further complicates the matters.

Healthcare system barriers: The absence of free or affordable SRS and cross-sex hormonal therapy in government hospitals is a central challenge for transgender people seeking gender transition-related services. Even in Tamil Nadu where free SRS is to be provided in a few government hospitals; only one government hospital in 
Chennai has a long-standing free SRS programme. In reality, free SRS is relatively inaccessible to many transgender people in other parts of Tamil Nadu. These study findings suggest that lack of explicit hospital policies that allow SRS coupled with moral positions taken by healthcare providers toward these procedures might also contribute to the failure of government hospitals to routinely offer these services. For example, one government hospital appointed an 'ethical committee' to examine whether SRS can be offered to a hijra-identified person as doctors felt it was 'unethical to harm a biologically normal male body'. Doctors are concerned about potential adverse legal implications if they offer surgery or prescribe female hormones to biological males. For example, even though there are no specific laws for or against SRS, many doctors are worried that they could be sued by the parents for changing their child's sex (even if the 'child' is a legal major) or even by the patients themselves if something goes wrong. Under Section 320 of the Indian Penal Code (IPC) 'emasculation' (in the legal context, removal of the testis or 'castration') is, however, explicitly mentioned as a grievous injury and a punishable offense, irrespective of the consent of the person who has been castrated. Similarly, doctors are unclear about the legal implications of prescribing female hormones to self-declared transgender people or hijras, especially those who have not undergone a formal psychological assessment. These dynamics are exemplified by doctors' practice of prescribing hormones on plain paper rather than on official prescription pads.

\section{Personal Issues}

Much like coming to terms with one's identity as lesbian, gay or bisexual, coming to terms with one's identity as a transgendered person often involves a tremendous inner struggle for self-acceptance. Personal issues include:

a) Shame, fear, and internalized transphobia and homophobia

b) Disclosure and coming out

c) Adjusting, adapting, or not adapting to social pressure to conform

d) Fear of relationships or loss of relationships

e) Self-imposed limitations on expression or aspirations

\section{Conclusion}

Despite receiving some recognition and social acceptance, TG's remain an ostracized and differentiated social class. TG struggle to reconcile their physical visibility with the invisibility of their community as a whole. In the end, however, community invisibility makes TG's susceptible to gender violence and other human rights abuses. By creating and recognizing transgender rights, India has the capacity to battle its current HIV/AIDS epidemic in a meaningful way, give real effect to the human rights of sexual minorities, and serve as a model for other nations to recognize gender-based rights. In order to accomplish these goals, however, India must repeal current discriminatory laws and enact equal opportunity legislation on the basis of gender and sexuality. In order for there to be meaningful change, formal legislation must be passed, and with the help of the human rights activists and unions, the legislation could very well happen.

\section{Acknowledgements}

The author would like to thank the editor for their valuable time and advice. 


\section{References}

Beattie, T. S., Bhattacharjee, P., Ramesh, B. M., Gurnani, V., Anthony, J., Isac, S., ... \& Blanchard, J. F. (2010). Violence against female sex workers in Karnataka state, south India: impact on health, and reductions in violence following an intervention program. BMC public health, 10(1), 476.

Bunch, C. (1995). Transforming human rights from a feminist perspective. Women's rights, human rights: International feminist perspectives, $11,158$.

Chakrabarti, S. (2009, January). Gender dimensions of the informal sector and informal employment in India. In Global forum on gender statististics (pp. 26-28).

Chakrapani, V. (2010). Hijras/transgender women in India: HIV, human rights and social exclusion.

Chettiar, A. (2015). Problems faced by Hijras (male to female transgenders) in Mumbai with reference to their health and harassment by the police. International Journal of Social Science and Humanity, 5(9), 752.

Gibson, R. B. (2006). Beyond the pillars: sustainability assessment as a framework for effective integration of social, economic and ecological considerations in significant decision-making. Journal of Environmental Assessment Policy and Management, 8(03), 259-280.

Heyes, C. J. (2003). Feminist solidarity after queer theory: The case of transgender. Signs: Journal of Women in Culture and Society, 28(4), 1093-1120.

Iriani, D. H. (2018). The Effect of Early English Learning on Psychology. International Journal of Social Sciences and Humanities (IJSSH), 2(1), 65-74.

Khan, S. I., Hussain, M. I., Parveen, S., Bhuiyan, M. I., Gourab, G., Sarker, G. F., ... \& Sikder, J. (2009). Living on the extreme margin: social exclusion of the transgender population (hijra) in Bangladesh. Journal of health, population, and nutrition, 27(4), 441.

MacDonald, E. (1998). Critical identities: rethinking feminism through transgender politics. Atlantis: Critical Studies in Gender, Culture \& Social Justice, 23(1).

Naik, A. K. (2009, September). Informal sector and informal workers in India. In Special IARIW-SAIM Conference on 'Measuring the Informal Economy in Developing Countries' September (pp. 23-26).

Sudimahayasa, N., Dantes, N., Candiasa, I. M., \& Natajaya, I. N. (2018). The contribution of psychological maturity and knowledge management in the developing sustainable professional development of productive programme teachers at public senior vocational schools in Bali. International Research Journal of Engineering, IT and Scientific Research (IRJEIS), 4(3), 12-16.

Thaler, C. (2007). Representing Transgender Clients. GPSolo, 24(3), 18-52. 